\title{
Letters
}

\section{Chlamydia pneumoniae infection and coronary heart disease}

\section{Trials should assess whether antibiotics eliminate organism from atherosclerotic lesions}

EDITOR-Gupta and Camm put the case for Chlamydia pneumoniae being involved in atherogenesis and outline possible mechanisms. ${ }^{1}$ As they point out, it is nearly 10 years since $C$ pneumoniae was linked serologically with coronary heart disease. Interest might have waned but for Shor's observation, which was followed by international collaboration. ${ }^{2}$ Shor was the first to suspect the existence of $C$ pneumoniae in the wall of atheromatous coronary arteries. Although some have disagreed, ${ }^{3}$ the cumulative observations of other workers leave no doubt that $C$ pneumoniae often occurs in atheromatous coronary and other large arteries, sometimes in a viable form, ${ }^{4}$ and significantly less often in normal vessels.

As Gupta and Camm indicate, however, whether $C$ pneumoniae initiates disease or invades after atherosclerosis has begun is unknown. If the latter, then whether it behaves as a bystander or potentiates chronic disease is also unknown. The possibility of a primary role might be looked at best by studies of early lesions in young people and by observations in animal models. Since $C$ pneumoniae is sensitive to several antibiotics, the desire to set up extensive placebo controlled trials to help to determine its role is understandable. It seems sensible, however, to assess first whether such antibiotics eliminate $C$ pneumoniae from atherosclerotic lesions. A reduction in the occurrence of $C$ pneumoniae in vascular tissues of patients treated before repair of an aortic aneurysm or other vascular surgery compared with patients untreated would be suggestive.

In deciding who should receive antibiotics in epidemiological studies, particularly in patients without a history of obvious coronary disease, a relatively non-invasive test that indicated whether $C$ pneumoniae was likely to be a factor in the lesion would be helpful. In individual patients, serological testing is unlikely to indicate who has $C$ pneumoniae in atheromatous vessels, ${ }^{4}$ but detection of the organism in peripheral blood monocytes may be helpful. ${ }^{4}$ However, the relation of monocytes that are positive for $C$ pneumoniae to arterial lesions that are positive has yet to be determined. Of course, antibiotic treatment, while hopefully reducing the occurrence of life threatening events, may not in itself define whether $C$ pneumoniae is a culprit. Antichlamydial drugs inhibit other organisms that could be involved. It is noteworthy that Mycoplasma pneumoniae behaves like $C$ pneumoniae epidemiologically and has similar antibiotic susceptibility and a capacity to cause chronic disease with autoimmune sequelae. Furthermore, $M$ gallisepticum in turkeys has a tropism for arterial walls. ${ }^{5}$ Finding $C$ pneumoniae in atheromatous arteries is potentially profoundly important, but to keep the options open would seem prudent at this stage.

David Taylor-Robinson Emeritus professor Department of Genitourinary Medicine and Communicable Diseases, Imperial College School of Medicine at St Mary's, London W2 1NY

1 Gupta S, Camm AJ. Chlamydia pneumoniae and coronary heart disease. $B M J$ 1997;314:1778-9. (21 June.)

2 Shor A, Kuo CC, Patton DL. Detection of Chlamydia pneumoniae in coronary arterial fatty streaks and atheromatous plaques. $S$ Afr Med J 1992;82:158-61.

matous plaques. S Afr Med J 1992;82:158-61. Weiss SM, Roblin PM, Gaydos CA, Cummings P, Patton DL, Schulhoff N, et al. Failure to detect Chlamydia pneumoniae in coronary atheromas of patients under-

4 Maass M, Krause E, Krüger S, Engel PM, Bartels C. Coronary arteries harbour viable Chlamydia pneumoniae. Fourth international symposium on modern concepts in endocarditis and cardiovascular infections, Yverdon-LesBains, Switzerland, May 1997. (Abstract No 101.)

5 Clyde WA, Thomas L. Tropism of Mycoplasma gallisepticum for arterial walls. Proc Natl Acad Sci 1973;70:1545-9.

\section{Role of $C$ pneumoniae in pathogenesis of} atherosclerosis must be determined

Editor-Gupta and Camm report that Chlamydia pneumoniae has been associated with coronary artery disease and atherosclerosis both in seroepidemiological studies and by the demonstration of the organism. ${ }^{1}$ Fong et al reported on the rabbit model for $C$ pmeumoniae infection and its complications, particularly atherosclerosis, stating that they had identified and isolated $C$ pneumoniae from the aorta and that there was evidence of early and intermediate changes of atherosclerosis. ${ }^{2}$ They also reported that the fact that $C$ pneumoniae had been identified in various stages of atherosclerosis suggested that it had an intimate pathogenic role, but it could also be an innocent bystander. As $C$ pneumoniae remains viable in the body long after acute infection has subsided, this conclusion seems to agree with results of previous studies.

Raised serum antibodies to $C$ pneumoniae and the presence of circulating immune complexes specific for chlamydia have been found in C pneumoniae infection. Laurila et al suggested that the altered serum lipid values going atherectomy. J Infect Dis 1996;173:957-62. in Finnish men with specific $\operatorname{IgG}$ antibodies to $C$ pneumoniae might be caused by the infection. $^{3}$ There are $\mathrm{T}$ cells in early atherosclerotic lesions that proliferate in response to some microbiological antigens. Heat shock proteins may be a key antigen in an autoimmune component of atherosclerosis, and various microbiological agents including chlamydia may play a part.

Cytomegalovirus has also been associated with coronary artery disease and atherosclerosis. ${ }^{4}$ It is thought to induce an inflammatory reaction of polymorphonuclear leucocytes against endothelial cells. Endothelial cells are one of the main targets for cytomegalovirus infection and may also be a site of persisting infection. There is no evidence of the presence of endothelial cells infected with $C$ pneumoniae in patients with chronic $C$ pneumoniae infection. Macrophages infected with $C$ pneumoniae may infect activated endothelial cells as the macrophages cross the vessel wall. Unlike infection with $C$ trachomatis, chronic infection with $C$ pneumoniae seems not to occur in monocytemacrophages. ${ }^{5}$

Atherosclerosis is pathologically similar to a chronic inflammatory response. Further studies are necessary to establish the role of

\section{Advice to authors}

We receive more letters than we can publish:we can currently accept only about one third. We prefer short letters that relate to articles published within the past four weeks. We also publish some "out of the blue"letters, which usually relate to matters of public policy.

When deciding which letters to publish we favour originality, assertions supported by data or by citation, and a clear prose style. Letters should have fewer than 400 words (please give a word count) and no more than five references (including one to the BMJ article to which they relate);references should be in the Vancouver style. We welcome pictures.

Letters, whether typed or sent by email, should give each author's current appointment and full address. Letters sent by email should give a telephone and fax number when possible. We encourage you to declare any conflict of interest. Please send a stamped addressed envelope if you would like to know whether your letter has been accepted or rejected.

We may post some letters submitted to us on the world wide web before we decide on publication in the paper version. We will assume that correspondents consent to this unless they specifically say no.

Letters will be edited and may be shortened. 
chronic $C$ pneumomiae infection in the pathogenesis of the disease. As Gupta and Camm report, however, trials to eradicate chlamydia with antibiotics may help to clarify the role of $C$ pneumoniae in the pathogenesis of coronary artery disease.

Kei Numazaki Assistant professor of paediatrics Shunzo Chiba Professor and Chairman Department of Paediatrics, Sapporo Medical University, School of Medicine, Sapporo, Japan numazaki@serpent.cc.sapmed.ac.jp

1 Gupta S, Camm AJ. Chlamydia pneumoniae and coronary heart disease. BMJ 1997;314:1778-9. (21 June.)

2 Fong IW, Chiu B, Viira E, Fong MW, Jang D, Mahoney J. Rabbit model for Chlamydia pneumoniae infection.J Clin Microbiol 1997;35:48-52.

3 Laurila A, Bloigu A, Näyhä S, Hassi J, Leinonen M, Saikku P. Chlamydia pneumoniae antibodies and serum lipids in Finnish men: cross sectional study. BMJ 1997;314:1456-7. (17 May.)

4 Numazaki K, Chiba S. Cytomegalovirus infection and restenosis. Stroke 1997;28:1088-90.

5 Numazaki K, Suzuki K, Chiba S. Replication of Chlamydia trachomatis and $\mathrm{C}$ pneumoniae in human monocytic cell line U-937. J Med Microbiol 1995;42:191-5.

\section{Other infections might have role in South Asians}

EDITOR-In their editorial Gupta and Camm explored the possible role of infection in the pathogenesis of atherosclerosis, ${ }^{1}$ as others have done in the $B M J$ recently. ${ }^{23}$ It is well known that the prevalence and incidence of and mortality from coronary heart disease in South Asians are increased. ${ }^{4}$ South Asians are more likely to be exposed to infections such as malaria and hepatitis and also to malnutrition and toxins. This results in transient or persistent derangement of the hepatic enzyme system, with deleterious effects on lipid metabolism, synthesis of coagulation factors, and immune reactions. All these in isolation or in combination constitute additional risk factors for South Asians, which are neglected: I have not come across any work on this, and so am unable to support my view by citation.

I hope that my suggestion that these factors have a role will encourage others to develop an alternative direction in further investigations.

S M Tauzeeh Staff grade physician

Finchley Memorial Hospital, London N12 0JE

1 Gupta S, Camm AJ. Chlamydia pneumoniae and coronary heart disease. BMJ 1997;314:1778-9. (21 June.)

2 Laurila A, Bloigu A, Näyhä S, Hassi J, Leinonen M, Saikku P. Chlamydia pneumoniae antibodies and serum lipids in Finnish men: cross sectional study. BMJ 1997;314:1456-7 (17 May.)

3 Parente F, Maconi G, Imbesi V, Sangaletti O, Poggio M,

Rossi E, et al. Helicobacter pylori infection and coagulation in healthy people. BMJ 1997;314:1318-9. coagulation
(3 May.)

4 Balarajan R. Ethnicity and variation in nations' health. Health Trends 1995;27:114-20.

\section{Changes in PLAB examination will have implications for overseas doctors}

EDITOR-Cassell and Goode's article on attaining competence in English, published in Career Focus, ${ }^{1}$ does not refer to imminent changes in the examination set by the Professional and Linguistic Assessments Board. From next year this examination will include an objective structured clinical and oral examination. ${ }^{2}$ This has several potential implications for overseas doctors. The objective structured clinical and oral examination is likely to increase the cost of the examination (exact figures are not yet known). The extra focus on clinical skills, although consistent with current trends in the assessment of competence, will make the need for clinical attachments (briefly mentioned in the article) much more important.

Anita Berlin Senior lecturer

Department of Primary Health Care and General Practice, Imperial College School of Medicine, London W2 1PG

Paramjit Gill Senior lecturer

Department of Primary Care and Population

Sciences, University College London and Royal

Free Hospital Medical School, London N19 5NF

Richard Stone Chair

Jewish Council for Racial Equality, 22 Seymour

Place, London W1 6AT

1 Cassell J, Goode L. Attaining competence in English [career focus]. BM] 1997;314:S2-3. (28 June.)

Professional and Linguistic Assessments Board. Report to the overseas committee of the General Medical Council. London: the overseas committee of the General

\section{Chronic disease in institutionalised patients}

\section{Housebound diabetic patients can also be forgotten}

EDitor-Benbow et al described the care of elderly diabetic patients in institutions, highlighting the inadequate provision of diabetic care. ${ }^{1}$ I believe that many of their comments could also be applied to housebound diabetic patients in the community.

In 1995 I surveyed the provision of diabetic care in my practice in Frinton on Sea, Essex. The practice had 6721 patients, of whom 19 diabetic patients were identified as being housebound-that is, unable to attend a diabetic clinic at the surgery. Of these, nine lived in their own home and 10 in institutions. Only three $(16 \%)$ of the housebound diabetic group had had a documented diabetic review in the past year (two at home and one in a residential home). By comparison, $62 \%$ of a random 100 diabetic patients who could attend the surgery had had an annual review.

Elderly housebound or institutionalised diabetic patients are a high risk group and would benefit from being specifically targeted by the primary health care team.

Stephen Moore General practitioner

Caradoc, Station Approach, Frinton on Sea, Essex CO13 9EE 1 Benbow SJ, Walsh A, Gill GV. Diabetes in institutionalised
elderly people: a forgotten population? BMJ 1997; 314:1868-9. (28 June.)

\section{British Geriatrics Society has produced document on diabetes care}

EDITOR-Throughout Britain, information on the incidence of, provision of care for, and outcome of diabetes among elderly people living in residential and nursing homes has been generally scant and unfocused. Benbow et al's survey ${ }^{1}$ complements our own research, in which we undertook objective assessments of cognitive and physical disability. ${ }^{2}$ In addition we ascertained the level of basic knowledge of diabetes among both staff and diabetic residents. ${ }^{2}$

Like Benbow et al, we found that input from health professionals into both residential and nursing homes was fragmented, with the involvement of both community nurses and dietitians being relatively rare. We too found higher levels of arterial disease and foot ulceration in the diabetic residents than in non-diabetic residents (matched for age and sex) living in the same homes. We also showed significant increases in dementia, cognitive impairment, and levels of dependency in the diabetic residents. Knowledge of diabetes was poor among both diabetic and non-diabetic residents and care staff.

We have been aware for some time of concerns about unstructured and often absent specialist diabetes care in institutions. This has prompted the special interest group of the British Geriatrics Society to produce a document intended for all health professionals who deliver diabetes care to residents in nursing and residential homes, including primary care doctors, diabetologists, and geriatricians with a special interest in diabetes. ${ }^{3}$ It characterises residents with diabetes in terms of their physical and mental characteristics, and sets out to establish a series of guidelines that promote more effective diabetes care.

We have echoed Benbow et al's suggestion that each district should consider appointing diabetes specialist nurses to promote diabetes care in institutions, and we have gone further to suggest that all diabetic residents should be on local diabetes registers where they exist. This will ensure that at least some will be recognised and, hopefully, have their care plans developed. The British Diabetic Association is considering proposals to set up a working party to look at diabetes care in institutions and to set national guidelines.

A J Sinclair Professor of geriatric medicine

University of Birmingham, Department of Geriatric Medicine, Selly Oak Hospital,Birmingham B29 6JD

A J Bayer Research fellow

University of Wales College of Medicine, Cardiff CF64 2XX

1 Benbow SJ, Walsh A, Gill GV. Diabetes in institutionalised elderly people: a forgotten population? BMJ 1997; 314:1868-9. (28 June.)

Sinclair AJ, Allard I, Bayer AJ. Observations of diabetes care in long-term institutional settings with measures of cognitive function and dependency. Diabetes Care 1997;20:778-84.

3 Sinclair AJ, Turnbull CJ, Croxson SCM. Document of care Sinclair AJ, Turnbull CJ, Croxson SCM. Document of care
for residents in residential and nursing homes. Postgrad MedJ(in press)

Care is worse for several chronic diseases in institutionalised patients

EDITOR-Benbow et al identified a group of diabetic patients with suboptimal care and high level of morbidity-elderly patients who were institutionalised. ${ }^{1}$ It would have been interesting to know if the deficiencies in care were due to their advanced age or the fact that they were institutionalised.

I recently audited the care of chronic disease in the 17 institutionalised patients (15 in 
Frequency of review of chronic disease in 12 residents of residential homes and 12 patients living in their own home who were matched for age, sex, and chronic disease

\begin{tabular}{lcc} 
& $\begin{array}{c}\text { Residents of } \\
\text { residential } \\
\text { homes }\end{array}$ & $\begin{array}{c}\text { Patients } \\
\text { living in } \\
\text { their own } \\
\text { home }\end{array}$ \\
\hline Average age & $\begin{array}{c}83 \text { years } \\
8 \text { months }\end{array}$ & $\begin{array}{c}82 \text { years } \\
1 \text { month }\end{array}$ \\
\hline $\begin{array}{l}\text { No whose chronic condition } \\
\text { was reviewed in past } \\
12 \text { months }\end{array}$ & 5 & 9 \\
\hline $\begin{array}{l}\text { Average time since last review } \\
\text { of condition (months) }\end{array}$ & 16 & 7 \\
\hline $\begin{array}{l}\text { Average No of consultations } \\
\text { with GP in past year }\end{array}$ & 11.2 & 8.0 \\
\hline GP=General practitioner. & & \\
\hline
\end{tabular}

residential homes, two in nursing homes) in my practice (list size 2960). I looked at four chronic diseases (diabetes, hypertension, ischaemic heart disease, and anaemia), which were present in 12 of the patients. These patients were matched by age, sex, and chronic disease with patients who lived in their own home. The table shows the results. The institutionalised patients were far less likely to have their condition reviewed than equivalent patients living in their own home. This was despite the fact that they had more acute consultations than patients in their own home and greater morbidity.

There are numerous reasons for this disappointing result. Institutionalised patients rarely attend the surgery, where most management of chronic disease occurs. Visits to homes for the elderly are often rushed, and residents may be seen quickly when the doctor attends to visit another patient. Many institutionalised patients have cognitive problems, which may make preventive care difficult. Despite these structural reasons, institutionalised patients deserve better care of chronic disease, and a named member of staff (general practitioner, practice nurse, or health visitor) should be designated to ensure that they are not a forgotten population.

David Molyneux General practitioner

Harambee Surgery, Trawden, Lancashire BB8 8QU

1 Benbow SJ, Walsh A, Gill GV. Diabetes in institutionalised elderly people: a forgotten population? BMJ 1997;314: 1868-9. (28 June.)

\section{Using liaison nurses can improve follow up and care}

EDITOR-Benbow et al comment on the forgotten population of diabetic residents in nursing homes and the need to provide guidelines for their management at a district level. ${ }^{1}$ We share their anxieties but believe that this is just the tip of the iceberg. We are concerned about communication and the access of residents of care homes to NHS based multidisciplinary care. If patient care is to be improved and common strategies developed, closer links between the NHS and private care homes must be developed. We have recently described a method of developing this area of liaison ${ }^{2}$ and can now report our preliminary findings from 300 patient discharges.
A liaison nurse followed up patients discharged to independent care homes from all specialties at Airedale NHS Trust. It was crucial to ensure that the work was not perceived as critical of the independent sector. We therefore based our work on validated assessment scales completed at discharge and on follow up in the care homes. The staff of the care homes were encouraged to discuss problems and make comments.

At the one week follow up visit (mean 8 (range 3-15) days after discharge) 286 patients were still resident. On 90 occasions written communication had either not been received (27) or was thought to be inadequate (63). We suspect that as our relationship with the independent sector has developed, expectations have increased and there is a greater willingness to highlight problems. The liaison nurse has facilitated an improvement in the provision of written communication: for the last 100 patient episodes this was not received on only three occasions. A standardised transfer sheet has now been developed in an attempt to improve the quality of information.

Action was taken on 116 visits. On 87 visits advice was given directly or an educational need explored-for example, instruction in the use of syringe drivers and assessment scales, administration of subcutaneous fluids, prevention of pressure sores, and principles of infection control. After 69 visits the liaison nurse had to make contact with one or more disciplines, most commonly with a consultant physician (21), day hospital team (13), or physiotherapist (13).

Our approach is simple and inexpensive and has been well received by the proprietors of the care homes visited. It enhances patient care and helps to improve standards in both the NHS and the independent sectors. It provides a springboard for further innovation.

J Paul Milnes Consultant physician

Sue Cochrane Liaison nurse

Janet Henderson Research and development manager Department of Medicine for the Elderly, Airedale NHS Trust, Keighley, West Yorkshire BD20 6TD

1 Benbow SJ, Walsh A, Gill GV. Diabetes in institutionalised elderly people: a forgotten population? BMJ 1997; 314:1868-9. (28 June.)

2 Cochrane S. Bridging the gap in care. Nursing Times 1997:93:38-9.

\section{Advice on long term corticosteroid treatment will be clarified}

Editor-Gibson and Prowse have pointed out an apparent contradiction between the current clinical practice of withdrawal of systemic corticosteroid treatment after short courses and an article in the February edition of Current Problems in Pharmacovigilance. ${ }^{2}$ The article was stimulated by concerns about the safety of systemic corticosteroid treatment and recent changes to the product information for these medicines in Britain. The article provided an overview of the adverse effects of the products and gave advice to doctors and pharmacists on how to prescribe and dispense them safely. Particular attention was given to the need to provide all patients with adequate advice on the reasons for treatment and possible adverse effects and to ensure that all patients received the patient information leaflet.

Although the section of the article on withdrawal of treatment provided the same advice as has been given in the British National Formulary, it has prompted requests for further information and clarification. In response to these the Committee on Safety of Medicines and the Medicines Control Agency have set up an expert working group to consider the issues further. We intend to publish our conclusions in order to clarify the advice given to health professionals.

P Arlett Secretary to editorial board, Current Problems in Pharmacovigilance, Medicines Control Agency M Rawlins Chairman, Committee on Safety of Medicines

Market Towers, London SW8 5NQ

1 Gibson GJ, Prowse K. Advice on long term corticosteroid treatment may be misleading. BMJ 1997;315:56-7. (5 July.) 2 Medicines Control Agency, Committee on Safety of Medicines. Prescribing systemic corticosteroids safely. Curr Probl cines. Prescribing systemic co
Pharmacovigilance 1997;23:4.

\section{Screening for genital chlamydial infection in women in general practice}

\section{Psychological effects of such screening are important}

EDITOR-I support Grun et al's call for a rigorous economic evaluation of screening for genital chlamydial infection, but the psychological aspects of screening deserve more attention. ${ }^{1}$ When considering the introduction of a screening programme it is essential to take the patients' psychological perspective into account, for several reasons. ${ }^{2}$

Firstly, no screening programme can succeed without the compliance of the target population with testing, treatment, and, in the case of a sexually transmitted disease, contact tracing. Secondly, the programme needs to be set up so as to minimise the negative psychological sequelae of screening, such as anxiety and depression. This is an especially important consideration when screening for genital chlamydial infection because of the potential for psychosexual problems and the implications for women's relationships with their partners if results of testing are positive. ${ }^{3}$ Finally, any medical interaction has the potential to be used as an opportunity for health promotion, and discussion of chlamydial infection would allow an improvement in knowledge and behaviour in this area of sexual health.

Screening for disease when this has not been requested by the patient raises ethical concerns, which are particularly pertinent when testing for a sexually transmitted disease. ${ }^{4}$ It would thus have been interesting to know how the patients' consent was obtained in this study. It would also have been interesting to know how much information about chlamydial infection was 
given in order to achieve a balance between obtaining adequately informed consent, providing health education, and avoiding provoking excessive anxiety.

The authors state that women who were positive on testing were contacted directly by the study nurse, who then arranged contact tracing in either a genitourinary medicine clinic or general practice. The paper could usefully have mentioned how this information was given; whether discussions with the patient at this stage covered how the infection might have been acquired and the fact that it may have a long dormant period; and whether any difficulties were encountered when the patients were told that they had been found to be positive for a sexually transmitted disease. The mode of informing patients of cervical cytological abnormalities has been shown to have an impact on subsequent psychological adjustment. ${ }^{5}$

The psychological effects of screening for genital chlamydial infection have not been sufficiently researched and could be as central as clinical and economic considerations when the introduction of a screening programme is being planned.

Miriam Santer Higher professional training fellow Department of General Practice, University of Edinburgh, Edinburgh EH8 9DX

1 Grun L, Tassano-Smith J, Carder C, Johnson AM, Robinson A, Murray E, et al. Comparison of two methods of screening for genital chlamydial infection in women attending in general practice: cross sectional survey. BMJ 1997;315:226-30. (26 July.)

2 Marteau TM. Psychology and screening: narrowing the gap between efficacy and effectiveness. Br J Clin Psychol gap between

3 Dryden MS, Wilkinson M, Redman M, Millar MR. Detection of Chlamydia trachomatis in general practice urine samples. BrJ Gen Pract 1994;44:114-7.

4 Burke P. The ethics of screening. In: Hart CR, Burke P, eds. Screening and surveillance in general practice. Edinburgh: Churchill-Livingstone, 1992.

5 Wilkinson C, Jones JM, McBride J. Anxiety caused by abnormal result of cervical smear test: a controlled trial BMJ 1990;300:440.

\section{More demographic information is needed on study population}

EDITOR-Grun et al found that the estimated prevalence of chlamydial infection in asymptomatic sexually active women aged 18-35 attending general practice was 2.6\%. ${ }^{1}$ They suggest that this figure is consistent with the findings of other recent studies and that "previous studies showing a higher prevalence have focused on subgroups at risk-for example, those seeking termination of pregnancy, complaining of genitourinary symptoms, or of social class III, IV, or V." Both these statements are worthy of further debate.

Firstly, comparing data from prevalence studies is difficult because one is not comparing like with like. Published prevalence studies in general practice have had small sample sizes and used a wide range of sampling and testing methodologies. Consequently, estimated prevalences of chlamydial infection in asymptomatic women attending general practice for a cervical smear test vary widely (range $2 \%$ to $12 \%$ ). ${ }^{23}$

Secondly, the authors provide incomplete information about the demography of their study sample and the population from which the sample was drawn. In particular, information is lacking about two important potential confounders: social class and ethnicity. This is surprising given that the authors define women from social class III, $\mathrm{IV}$, or $\mathrm{V}$ as a subgroup at risk of infection.

The study population consisted of two distinct groups: 2051 women aged 20-35 attending for cervical smear testing and 204 women aged 18-19 invited to attend a "young well woman" check. The setting was four general practices in northeast London between October 1994 and January 1996. No other demographic information is provided.

The study sample consisted of 890 women drawn non-randomly from the above two groups. This represented $40 \%$ of all eligible women. No information is provided about the characteristics of those women who were not screened; nor is information given about the social class and ethnicity of those who were screened, although the authors do compare their behavioural characteristics with the results of the sexual attitudes and lifestyles survey. ${ }^{4}$

The lack of demographic information means that it is difficult to determine the representativeness of the study population, and it is therefore not possible to extrapolate the study's results to estimate the likely prevalence of genital chlamydial infection in asymptomatic women attending general practice. The prevalence of genital chlamydial infection in Britain needs to be accurately estimated with standardised testing techniques in a representative cross section of women before any recommendation can be made regarding selective screening strategies. $^{23}$

Tim Stokes Clinical lecturer in general practice Department of General Practice and Primary Health Care, University of Leicester, Leicester LE5 4PW

Rashmi Shukla Consultant in communicable disease control

Leicestershire Health, Leicester LE5 4QF

Paul Schober Consultant in genitourinary medicine Leicester Royal Infirmary, Leicester LE1 5WW

1 Grun L, Tassano-Smith J, Carder C, Johnson AM, Robinson A, Murray E, et al. Comparison of two methods of screening for genital chlamydial infection in women attending in general practice: cross sectional survey. $B M J$ 1997;315:226-30. (26 July.)

2 Simms I, Catchpole M, Brugha R, Rogers P, Mallinson H, Nicoll A. Epidemiology of genital Chlamydia trachomatis in England and Wales. Genitourin Med 1997;73:122-6.

3 Stokes T Screening for chlamydia in general practice: literar Sceening for chlamydia in general practice: a literature review and summ
Health Med 1997;19:222-32.

Heallh Med 1997,19.222-32. Wellings K, Field J Sexil 4 Johnson AM, Wadsworth J, Wellings K, Field J. Sexual
attitudes and lifestyles. Oxford: Blackwell Scientific, 1994.

\section{Junior doctors need to work more than 48 hours a week}

EDITOR-Rory Watson reports that the European Commission is canvassing the degree of support for extending the 48 hour week to the small group of professions that was originally excluded from the legislation adopted in 1993. ${ }^{1}$ The social affairs commissioner, Padraig Flynn, said: "The exclusion of certain categories of workers from the general protection provided by the legislation is an anomaly which needs to be corrected." ${ }^{1}$ We believe that this should not include junior doctors. If working hours are reduced to 48 as proposed, it will be necessary to cover out of hours. One way to do this is to employ locum agency doctors, which is not in the best interests of inpatients.

We already work from 8 am to $5 \mathrm{pm}$, or even $6 \mathrm{pm}$. This is $45-50$ hours a week as regular basic work, mainly elective. All junior doctors gain their experience in the management of acute cases during out of hours periods. A balance between elective and emergency training is vital and ought to be preserved. Most consultants agree that the present 72 hour arrangement is too short. If this is reduced to 48 , what is next?

This dilemma could be solved if the 48 hour limit did not apply to time on call. ${ }^{2}$ This would bring us back to the present arrangement.

A M Hamade Senior house officer in general surgery Barnsley District General Hospital, Barnsley S75 2EP

\section{A K AlDabbagh Registrar}

Huddersfield Royal Infirmary, Huddersfield HD3 3EA

Watson R. European Commission looking to cut junior doctors' hours. BMJ 1997;315:207. (26 July.)

2 Noris R. 48-Hour week for juniors. Hosp Doctor 1997 July 24:1.

\section{Screening remand prisoners for drug misuse would be improved by training doctors better}

EDitor-In their case study of substance misuse by remand prisoners Mason et al found that "present prison procedures fail to identify the extent to which substances are used and misused in people newly remanded to prison." In a recent (unpublished) study of the health needs presented by prisoners remanded into La Moye prison, Jersey, I examined the 74 healthcare screens of men in custody on one day in 1996. I found that, when used by adequately trained healthcare staff with sufficient time, the screen is both a comprehensive and a reliable instrument for alerting staff to the health needs of prisoners (table). The health screen used by La Moye prison is identical with that used on the mainland. My findings, incidentally, were also closely comparable to the findings of Maden et al in their survey of mental disorder in remand prisoners in England and Wales. ${ }^{2}$

My study shows the validity of the health screen in fulfilling its purpose: to alert staff to

Details of alcohol consumption and drug misuse at La Moye prison compared with Durham prison (as reported by Mason et $\mathrm{al}^{1}$ ). Figures are numbers (percentages)

\begin{tabular}{lll} 
& $\begin{array}{c}\text { La Moye } \\
\text { prison } \\
(\mathbf{n = 7 4 )}\end{array}$ & $\begin{array}{l}\text { Durham } \\
\text { prison } \\
(\mathbf{n}=\mathbf{5 4 8 )}\end{array}$ \\
\hline Alcohol consumption: & & \\
\hline$<21$ units/week & $42(57)$ & $315(57)$ \\
\hline$>50$ units/ week & $17(23)$ & $116(21)$ \\
\hline Drug misuse: & & \\
\hline Used drugs at some time & $59(80)$ & $382(70)$ \\
\hline Admitted using drugs at & $29(39)$ & $181(33)$
\end{tabular}


the health needs of prisoners. The health screen in Durham prison failed to fulfil its purpose. Might this failure lie not with its design but with the staff who administer it or the circumstances in which they perform the task? I recognise, of course, that there is a vast difference between the large remand centre at Durham and the small prison at La Moye.

The assessment and treatment of drug misusers entering prison could be greatly improved if all healthcare staff and doctors concerned (most of whom are general practitioners) received training in taking a drug and alcohol history.

Rosemary J Wool Independent adviser on health care in secure environments

Wicken House, 105 Weston Road, Aston Clinton, Aylesbury, Buckinghamshire HP22 5EP

1 Mason D, Birmingham L, Grubin D. Substance use in remand prisoners: a consecutive study. BMJ 1997:315:1821. (5 July.)

2 Maden A, Taylor CJA, Brooke D, Gunn J. Mental disorder in remand prisoners. London: Department of Forensic Psychiatry, Institute of Psychiatry, 1995.

\section{Factors influencing relative weights of placenta and newborn infant}

\section{Maternal haemoglobin and blood pressure should have been regarded as continuous variables}

EDITOR-Williams et al suggest that maternal anaemia (which they define as a haemoglobin concentration of $<110 \mathrm{~g} / \mathrm{l}$ at any time in pregnancy) is related to birth weight, placental weight, and the placental weight to birthweight ratio. ${ }^{1}$ They used multiple regression and logistic analysis to examine the relation between the variables.

Maternal haemoglobin concentration should not be used as a dichotomised variable in this type of analysis, because its relation with birth weight is $\mathrm{U}$ shaped. ${ }^{2}$ Thus any single cut off will misrepresent the true correlation. Maximum birth weight is associated with a maternal haemoglobin concentration of 95-105 g/l, which is why anaemia in their analysis (including as it does the physiological optimum for birth weight) is associated with a higher birth weight than lack of anaemia (high haemoglobin concentrations do not indicate only absence of anaemia but can be due to a failure of plasma volume expansion, which is in turn associated with low birth weight). Use of a lower cut off (for example, $90 \mathrm{~g} / \mathrm{l}$ ) would have produced an opposite result.

A similar caveat applies to maternal blood pressure, both high and low blood pressures being associated with lower birth weights than intermediate values. I have analysed 22255 consecutive births at the West London/Chelsea and Westminster maternity unit; gestational age was recorded as 37-42 weeks (best estimate based on menstrual dates and results of early ultrasonography), the highest diastolic blood pressure in pregnancy was recorded as being between 30 and $130 \mathrm{~mm} \mathrm{Hg}$, and the birth weight was between 500 and $6000 \mathrm{~g}$ (unpublished data). If the maximum diastolic blood pressure was $61-70 \mathrm{~mm} \mathrm{Hg}$ the incidence of babies with a birth weight below the 10th centile (weight for gestational age by the nomograms of Altman and Coles ${ }^{3}$ ) was $2.63 \%(278 / 10555)$, whereas it was $3.65 \%$ $(125 / 3429 ; \chi 2=9.1, \mathrm{P}=0.0025$ two tailed $)$ if the maximum blood pressure was $\leqslant 60 \mathrm{~mm}$ $\mathrm{Hg}, 3.22 \%(221 / 6874 ; \chi 2=4.85, \mathrm{P}=0.027$ two tailed) if it was $71-89 \mathrm{~mm} \mathrm{Hg}$, and $6.87 \%$ $(96 / 1397)$ if it was $\geqslant 90 \mathrm{~mm} \mathrm{Hg}$.

The relation of placental weight and birth weight is likely to reflect a complex interaction of variables. An analysis that represented maternal haemoglobin concentrations and blood pressure as continuous variables that are suboptimal either side of the physiological range would be more informative. ${ }^{4}$

Philip Steer Professor

Academic Department of Obstetrics and Gynaecology, Charing Cross and Westminster Medical School, London SW10 9NH

1 Williams LA, Evans SF, Newnham JP. Prospective cohort study of factors influencing the relative weights of the placenta and the newborn infant. BMJ 1997;314:1864-8. (28 June.)

2 Steer PJ, Alam MA, Wadsworth J, Welch A. Relation between maternal haemoglobin concentration and birth weight in different ethnic groups. BMJ 1995;310:489-91.

3 Altman DG, Coles EC. Nomograms for precise determination of birthweight for dates. $\mathrm{Br} J$ Obstet Gynaecol 1980;87:81-6.

4 Steer PJ. The effect of maternal anaemia and iron deficiency on the ratio of fetal weight to placental weight. Br J Obstet Gynaecol 1992;99:271-2.

\section{Authors' reply}

EDITOR-Steer's concern that our use of maternal haemoglobin concentration as a dichotomised variable has inadvertently concealed information is an important issue, and we provide further details here. In our dataset there was no relation between haemoglobin measurements at 18 weeks' gestation and birth weight. After birth weights were adjusted for maternal smoking and size, gestational age at the time of birth, and sex of the infant, there was also no relation with haemoglobin concentration $(\mathrm{P}=0.152)$. For haemoglobin measurements at 34 weeks' gestation there was a negative relation with both birth weight and adjusted birth weight. There was an approximately $100 \mathrm{~g}$ reduction in birth weight between those infants whose mother's haemoglobin concentration was $<110 \mathrm{~g} / \mathrm{l}$ and those whose mother's haemoglobin concentration was above this value, with no suggestion of a $U$ shaped curve. This value provided an appropriate cut off distinguishing two apparent groups and enabled the analysis to reflect the relation between haemoglobin concentration and birth weight in our study population.

Our data on blood pressure were based on classification of hypertensive disorders rather than absolute values within the normal range. Nevertheless, our findings were similar to Steer's in that in hypertensive mothers we observed a higher proportion of infants with birth weight below the 10th percentile $(13.8 \%)$. However, the populations were clearly different in that $10.7 \%$ of infants from normotensive women in our study had birth weights below the 10th percentile, compared with $3.0 \%$ in Steer's population. Moreover, our prospective and extensive data collection from each pregnancy, including results of ultrasonographic dating at 18 weeks' gestation, enabled thorough adjustment for many covariates which are not available in retrospective studies. After such adjustment for covariates, particularly accurate gestational age, we observed that the relation between hypertension and birth weight was no longer significant.

Some of the discrepancies between results from these different studies highlight the thrust of the conclusions in our paper and show the need for care when comparing data obtained with different methodologies and at different times.

Sharon Evans Senior biostatistician

John Newnham Clinical professor

Lucy Williams Research fellow

Women and Infants Research Foundation, Department of Obstetrics and Gynaecology, University of Western Australia, King Edward Memorial Hospital, Perth, Australia

\section{Exercise is beneficial adjunctive treatment in depression}

EDITOR-Hale's article on depression in the ABC of Mental Health was presumably aimed at updating and informing people on the current thinking and treatments of depression. ${ }^{1}$ We are disappointed that it did not mention the use of exercise as an adjunctive treatment of depression.

There is now a growing body of evidence both from meta-analysis and from randomised control trials ${ }^{2}$ to show that exercise is beneficial in mild to moderate depression and may also be of use in more chronic and severe depression. ${ }^{3}$ In addition, people with mental illness exercise less than the general population, ${ }^{4}$ so exercise may have a protective function. Exercise also has relatively few adverse effects compared with many drug treatments. Patients often say that they do not want drug treatment, and exercise is a reasonable alternative. It is also cost effective since it is relatively cheap to provide.

Exercise is still, however, rarely offered as a treatment option or adjunct at psychiatric hospitals, clinics, or day centres. This reflects the problem of generalising research findings into everyday practice and perhaps even a reluctance to consider the link between body and mind. ${ }^{5}$ One way in which practice can be informed is by articles such as Hale's, and we regret that the article did not mention the potential that exercise may have in depression.

Sarah Beesley Lecturer

University Department of Psychological Medicine, Gartnavel Royal Hospital, Glasgow G12 0XH

Nanette Mutrie Senior lecturer

Institute of Biomedical and Life Sciences, University of Glasgow, Glasgow G12 8QQ

\footnotetext{
Hale A. ABC of mental health: depression. $B M J$ 1997;315:43-5. (5 July.)

2 North T, McCullagh P, Tran V. The effect of exercise on depression. Exerc Sports Sci Rev 1990;19:379-415.

3 Martinsen E, Hoffart A, Solberg O. Comparing aerobic and non-aerobic forms of exercise in the treatment of clinical depression: a randomised trial. Compr Psychiatry 1989;30:324-31
} 
4 Tsuang M, Perkins K, Simpson J. Physical diseases in schizophrenia and affective disorder. J Clin Psychiatry 1983;44:42-6

5 McEntee D, Halgin R. Therapists' attitudes about addressing the role of exercise in psychotherapy. J Clin Psychol 1996;52:48-60.

\section{Postgraduate education for general practitioners}

\section{Centrally funded scheme would not necessarily be better}

EDITOR-The conclusions of the report by the West of Scotland Postgraduate Medical Education Board on general practitioners attendances at postgraduate education activities are open to debate. ${ }^{1}$ The implied assertion that a centrally organised scheme is better than an open and free education market (working to professional standards) requires more evidence. After all, one of the most important reasons for introducing the postgraduate education allowance was to encourage personal responsibility for learning and development in general practice education and a move towards the concept of the purchaser-provider partnership.

Despite some of the limitations of the postgraduate education allowance, many exciting methods of education are now available to general practitioners. Distance based learning programmes, practice based educational activities, personal education plans, and portfolio learning now dominate continuing medical education and professional development. In addition, through the postgraduate education allowance system, skills have increased among a wide variety of providers, not all of whom can be tarred with the brush of promotional greed. A centralised system of education, as reported in the west of Scotland study, sounds like a minor variation of what was available before the postgraduate education allowance came into effect; that system was centrally directed, poorly attended, and, generally, irrelevant.

The more worrying conclusion of this study is that, somehow, when general practitioners choose an educational activity outside the central scheme, they do so purely for financial gain. This hints at a strange belief that people in the "centre" know better what is good for general practitioners than they do themselves. If that is the case then we need to clarify our commitment to the adult learning model, which has been the main plank of criticism (at times unfairly) of the postgraduate education allowance system. Either we genuinely believe in this model and respect the professional integrity of our colleagues who choose what is relevant to them or we do not, in which case we should seek more central control and power.

In summary, the postgraduate education allowance system, though by no means perfect, has brought about many positive changes in continuing medical education in general practice. It has enabled innovation in new methods of learning, encouraged personal responsibility for continuing professional development, and given the profession the opportunity to set standards for accreditation and monitoring. Maybe it is time to move on from the postgraduate education allowance, but surely we do not want to go back to the discredited days of centrally funded and organised postgraduate education.

Jamie Bahrami Director of postgraduate general practice education

practice education Dental Education (Yorkshire), University of Leeds, Leeds LS2 9JT

1 Murray TS, Campbell LM. Finance, not learning needs, makes general practitioners attend courses: a database survey. BMJ 1997;315:353. (9 August.)

\section{Interdisciplinary education would help improve teamwork}

EDITOR-In his editorial Toon identifies the difficulties that general practitioners face in trying to learn within a system that encourages the "never mind the quality, feel the width" philosophy of education. ${ }^{1}$ Although he rightly highlights the fact that patient care should be central to the educational system, he fails to broaden the debate to discuss the range of educational methods currently available, including the important but underdeveloped area of practice based interdisciplinary education.

Any new system must recognise that there is limited evidence that these educational methods change people's behaviour. Nevertheless, while we are waiting for relevant research to be commissioned we need to take a commonsense approach to encourage those methods which are more likely than not to produce this change.

Health care based in general practice is now a team activity, and there is general agreement that one of the main ways to produce effective teamwork is to encourage widespread interdisciplinary education. ${ }^{2}$ Our primary healthcare team has been organising regular programmes of practice based interdisciplinary education since 1991. We have confirmed that this type of education has advantages in terms of the relevance of material covered to our day to day work, the incorporation of audit activity, short times from having ideas to implementation, and the ability to keep people involved by the use of small groups. ${ }^{3}$

It would be exciting if our initiative was reproduced on a national scale, with primary health care delivered by well organised teams with access to expert educational advice. The teams would thus be able to identify their own learning needs and to commission their own education. This would require our present system of postgraduate education to be turned on its head and would demand a rethink of the present inadequate support structures.

Those who commission the education of the future should ask that patient need determines the curriculum and that primary healthcare teams are the participants. Such education is crying out for development, and adequate resources need to be found. Only when these working groups become learning groups are patients likely to benefit directly from the education of doctors.

W F Cunningham General practitioner

Corbridge Health Centre, Corbridge on Tyne, Northumberland NE45 5JW

1 Toon P. Educating doctors, to improve patient care. BM] 1997;315:326. (9 August.)

2 Calman K. Working together: team-work.J Interprofessional Care 1994;8:95-101.

3 Cunningham W. Interdisciplinary practice educational meetings-continuing education for the working primary health care team. Educ Gen Pract 1995;6:41-8.

\section{Lectures have many advantages}

EDITOR-Toon's editorial about educating doctors seems to fall below the standards of objectivity expected in a peer reviewed journal. ${ }^{1}$ The subtitle-"a choice between self directed learning and sitting in lectures struggling to keep awake"-does not suggest that the author is approaching the subject with an open mind. Denigration of the lecture system of learning may be fashionable, but anyone advocating its abandonment should state clearly the advantages of the proposed replacement. I think that some positive aspects of attendance at lectures should be pointed out.

Firstly, lectures provide a rapid means of updating oneself on subjects, which is valuable to general practitioners working long hours, who are rightly expected by their patients to have a wide background knowledge of all aspects of medicine. General practitioners might have difficulty absenting themselves from their practices for lengthier forms of updating.

Secondly, regular lectures provide a meeting place for general practitioners, who might otherwise be professionally isolated.

Thirdly, lectures provide the opportunity to meet specialists, who might otherwise simply be signatures at the end of hospital letters.

Fourthly, lectures provide the opportunity to question the approach taken by individual consultants and their units.

I submit that these aspects are important to morale and knowledge among general practitioners and are thus ultimately of great value to patient care. To measure the success of education solely in terms of changed clinical behaviour is far too narrow.

Toon seems to forget that general practitioners who use lectures also use other forms of self education, notably reading. $\mathrm{He}$ cites the paper of Murray and Campbell, who conclude from the fall in the numbers subscribing to the courses that they run that general practitioners are guided by financial considerations in their choice of formal postgraduate education. The data are compatible with that conclusion but also with other possible explanations, including geography, timing, workload, and the quality and relevance of the material offered. Murray and Campbell do not consider any of these, except to note that the fall in attendance at their courses was greatest for the health promotion topics (might this have been due to saturation coverage in previous years?) and that subscribers to their scheme had a greater appetite for material on the provision of services. 
Authors should avoid the risk of being thought to imply that general practitioners who do things differently from the way in which they would like to see them done are lazy or greedy.

James Barbour General practitioner

463 Springfield Road, Belfast BT12 7DN

1 Toon P. Educating doctors, to improve patient care. $B M J$ 1997;315:326. (9 August.)

\section{Meetings in postgraduate centres can be helpful}

EDitor-Toon draws attention to the inappropriateness of the current postgraduate educational allowance system of funding for continuing medical education for general practitioners. ${ }^{1}$ He adds that the NHS has a right to expect that the education it pays for will improve patient care.

To encourage general practitioners to obtain the education that is most likely to lead to improvements in the care of their patients, a programme must be designed to cater to their educational needs. One way of achieving this is to help general practitioners to develop their own personal learning plans. I am strongly in favour of this approach but do not believe that it is suited to all general practitioners.

I believe that a formal educational programme based in postgraduate centres can, if well designed, provide a complementary and satisfactory means of fulfilling those educational needs. The challenge, however, is to plan such a programme systematically. In Exeter we now have a regular programme, during which an expert, normally a local consultant, attends a seminar based meeting to comment and advise on clinical scenarios presented by the audience. The precise content of each meeting is therefore determined entirely by the participants, although the expert can draw the audience's attention to issues that he or she sees as important. This approach has received high marks on our feedback forms.

Having addressed the problem of making meetings in Exeter relevant, we are now debating how best to plan the content of the whole programme. We are setting up a committee - called "Improve Practice"-with representatives from primary care audit, the local research and development support unit, secondary care, and healthcare teams. This committee will meet regularly to review current issues of best practice in which education can facilitate improvements in patient care. I have written to all the local specialists offering to try to design an educational package if they can identify an area within their specialty in which the care of patients in primary care might be improved. In return, the specialists have agreed to receive constructive criticism about their practice.

One of the problems of the postgraduate education allowance is that it allows the Department of Health to think that it is adequately financing general practice education; in reality, little money exists for the development and planning of ambitious programmes. For example, general practice clinical tutors are paid one session a week to design programmes, organise meetings and courses, and run those courses-in my case for 200 general practitioners. Proper investment in education has potential for achieving considerably better value for money.

Phil Taylor General practice clinical tutor Exeter Postgraduate Medical Centre, Exeter EX2 5DW

1 Toon P. Educating doctors, to improve patient care. $B M J$ 1997;315:326. (9 August.)

\section{Evidence is needed that $\beta$ blockade alone reduces mortality in hypertension}

EDITOR-I am concerned by the oft repeated but incorrect statement that "reduction in mortality has been shown only with established $\beta$ blockers and diuretics," which is one of the key messages of Philipp et al's paper on the HANE study. ${ }^{1}$ I have no quarrel with the diuretic part of the statement, which is well supported by good trials. However, the idea that monotherapy with a $\beta$ blocker, as in the HANE study, can reduce mortality is simply incorrect.

Reference is made to the meta-analysis by Collins et al in $1990 .^{2}$ That meta-analysis was of 14 unconfounded studies, of which only two were on $\beta$ blockade. One was a small study in elderly people, ${ }^{3}$ which has now been superseded by the Medical Research Council's mega-study in elderly people. ${ }^{4}$ In the mega-study the $\beta$ blocker atenolol did not reduce mortality when compared with placebo (whereas the diuretic did). Cardiovascular mortality seemed to increase in the atenolol group. In the Swedish trial in old patients with hypertension, in which mortality was reduced, initial $\beta$ blockade was indeed one of the arms of treatment, but over two thirds of patients received an added diuretic. ${ }^{5}$ (If the proposal is that combined treatment with $\beta$ blockade and diuretic can reduce mortality then there are indirect supporting data from the Swedish trial.) In the Medical Research Council's trial in middle aged people, propranolol had only modest effects in non-smokers and conferred little or no benefit in smokers. Mortality was not decreased, and the trial was not powered for mortality. Two other studies that Philipp et al cite, in which mortality was reduced, refer to initial treatment with diuretics, not with $\beta$ blockers.

In this era of evidence based medicine, exactly where is the evidence that monotherapy with a $\beta$ blocker reduces mortality in hypertension?

L H Opie Director, heart research unit and hypertension clinic

Department of Medicine, UCT Medical School, Observatory 7925, Cape Town, South Africa Opie@samiot.uct.ac.za

1 Philipp T, Anlauf M, Distler A, Holzgreve H, Michaelis J, Wellek S, et al on behalf of the HANE Trial Research Wellek Group. Randomised, double blind, multicentre comparison of hydrochlorothiazide, atenolol, nitrendipine, and enalapril in antihypertensive treatment: results of the HANE study. BMJ 1997;315:154-9. (19 July.)

2 Collins R, Peto R, MacMahon S, Hebert P, Fiebach NH, Eberlein KA, et al. Blood pressure stroke and coronary heart disease. Part 2. Short term reductions in blood pres- sure: overview of randomised drug trials in their epidemiological context. Lancet 1990;335:827-38.

3 Coope J, Warrender TS. Randomised trial of treatment of hypertension in elderly patients in primary care. $B M J$ 1986:293:1145-51.

4 MRC Working Party. Medical Research Council trial of treatment of hypertension in older adults: principal results. treatment of hypertens

5 Dahlöf B, Lindholm LH, Hansson L, Scherstén B, Ekbom Dahlöf B, Lindholm LH, Hansson L, Scherstén B, Ekbom
T, Wester P-O. Morbidity and mortality in the Swedish trial in old patients with hypertension (STOP-hypertension) Lancet 1991;338:1281-5.

\section{Fees for opinions and information are not always justified}

EDITOR-As occupational physicians we regularly communicate with colleagues involved in the clinical care of employees. We believe it is good practice to do so when considering problems of attendance, long term absence, or return to work programmes.

Two developments concern us. The first is a tendency for a request for information to be met with a demand for money "up front." As a matter of routine, we offer and pay the rates recommended by the BMA for any report and a further exchange of letters serves merely to add delay. It is depressing to have a lack of trust so clearly demonstrated.

A second, and more serious, problem has recently arisen. A request to a consultant for his opinion on specific work activities in a complex case produced a response, not from him or his staff, but from the "patient affairs officer" of the hospital trust. A copy of medical records was offered, at a cost of $£ 100$, or a full medical examination plus report could be obtained for $£ 250$. Neither option was useful in the circumstances. A genuine effort to improve the management of the patient seems to have been diverted into an income generation scheme. We are appalled by this practice and ask that our clinical colleagues treat our requests for advice with respect, for the ultimate benefit of the patient.

Martyn J F Davidson Occupational physician Abigail M Sargent Occupational physician Iain A McCoubrey Occupational physician John Lewis Partnership Medical Service, London SW1E 5NN

\section{BMA remains impartial on professional issues in dispute between two consultants}

EDITOR-The BMA wishes to clarify its role in the professional dispute that has arisen between two consultants at Gateshead who specialise in obstetrics and gynaecological oncology. ${ }^{1}$ The consultants, Mr John Monaghan and Mr Debi Sinha, are both BMA members, and the association has been advising each of them individually on their contractual rights and obligations. Contrary to the implications of some reports, the BMA has always been and remains impartial on the professional issues at the root of the dispute.

E M Armstrong Secretary BMA, London WC1H 9JP

1 Campbell D. Cancer unit faces ministerial inquiry. BMJ 1997;315:1328. (22 November.) 